\title{
The crowding-out effect of the extrinsic motivation: An empirical study on the turnover intention of members of the youth social organization
}

\author{
Yuting Zhang \& Yong Li* \\ School of Public Affairs, Zhejiang University, Zhejiang, China
}

\begin{abstract}
The youth voluntary organization has been outstanding in the social governance. Therefore it's an important issue how to ensure its role played sustainably in the long term. Particularly in reality, a few youth voluntary organizations sometimes become lax and act no function due to the turnover of its members. So it can tell that it's given a very realistic meaning to discuss the factors influencing the turnover intention of the management of the organization. Based on the theory of organizational identification, the essay tries to find out the members' intrinsic motivation to join the youth voluntary organization and its impact on turnover intention, and to verify the regulating mechanism of extrinsic motivation to the organizational identification and the mediating mechanism of organizational identification to the turnover intention. The result of the study into members of the Zhejiang youth voluntary organization shows that: (1) the intrinsic intention has the most significant influence on the turnover of the members of the youth voluntary organization; (2) the organizational identification plays a mediating role between intrinsic motivation and turnover intention; (3) the relationship between intrinsic motivation and organizational identification will be moderated by extrinsic motivation. The result of this study releases a revelatory meaning to raise the organizational identification of the members and restrain their turnover intention.
\end{abstract}

Keywords: intrinsic motivation; extrinsic motivation; organizational identification; turnover intention

\section{BACKGROUND AND QUESTIONS}

In recent years, studies on turnover of the members of the non-profit organization have increased day by day (De Vita et al., 2002; Maertz \& Boyar, 2012). Indeed, as the public issues emerge endlessly, the pressure of social governance has also been enhanced. It's fully realized by various industries in the society that the involvement guarantees the augmenting of the whole governance level with non-profit organization for forming a pattern of cooperating governance where the government' market and society positively interact to each other. However, in the social organization where the concept of rule by man is thought highly, its members, whose turnover directly influences its service quality and sustainable development, are the foremost resource. Even though the youth social organization is the most dynamic and developable strength in the third department, its problem of members' turnover is the most serious too. There have been

*Corresponding author: liyonglisa1127@163.com a large amount of studies indicated that members' turnover would negatively influence the organization's efficiency, and then it influenced the achievement of its goal (Price, 2001; Hom \& Griffeth, 1995). Its negative effects are following: the loss of the human resources, the damage to the whole function of running, the burden of the members remain on the socialization and training toward the new and the growth of the operating cost, etc. (Salamon \& Geller, 2007) .

For a long time, the studies on their turnover are mainly expanded from environmental factor, personal factor and structural factor: environmental factor refers to the chance and the kinship responsibility; personal factor includes the training, job embeddedness, positive emotion and negative emotion, etc.; structural factor includes seven elements of autonomy, impartiality, work pressure, labor compensation, promotion space, convention and social support (Price, 2001). But the studies in the past didn't focus on the potential influence on the turnover intention of the motivation of personal participation. Keep the initial aim in mind and we can end well as we begin. Thus, to know the 
members' initial motivation to join the non-profit organization, and to develop the influencing factors of the original personal aspect, may provide us strategies and advice for the high rate of the members' turnover.

Based on the theory of social identification, the essay concentrates on the turnover of the members in voluntary organization. Generally speaking, identification means that, the individual acknowledges himself (or herself) as one in a particular social group, while realises the emotion and value significance as being one in the group. It emphasises the social nature of being a society-constructing self while avoids the views that separate self from society. The self becomes a multiple identification belonging to a specific practice activity (Georgellis et al., 2011). Organizational identification had been strengthened on the base of the concept of social identification since the 1950s (Chirkov et al., 2003). Many studies have shown, organizational identification can restrain turnover intention (Yousaf et al., 2015). So according to the reasons above, the essay tries to introduce two basic concepts - voluntary motivation and extrinsic motivation. And centring on organizational identification, it considers the function and mechanism of these factors to the turnover of youth social organization and management.

The essay firstly poses the assumptions through review the existing related theories and researches; secondly introduces its methods and hypothesis tests; finally discusses the result of this study, pointing out the limit and its future development.

\section{THEORIES AND ASSUMPTIONS}

\subsection{Voluntary motivation's negative influence on turnover intention}

Porter and Lawler (1968) came up with the model of voluntary motivation and extrinsic motivation of job. As they thought, voluntary motivation means that the reason driving people to undertake one activity is that they feel satisfied and interested; extrinsic motivation means that the driving power to undertake one activity doesn't some from the activity itself but the result of it (Gagné \& Deci, 2005). Non-profit organization features as non-profit purpose, autonomy and voluntariness. In general, the participants hold a strong voluntary motivation (voluntary motivation/altruistic motivation), that's to say, individual tends to willingly take the positive behaviour beyond return for others' benefits (Lester et al., 2008). In other words, this voluntary and other-orientation behaviour mainly origins from personal values and the act of intrinsic motivation (Clary et al., 1998), and the individual also gets self-satisfaction from it. That's why the members prefer to stay as their self-satisfaction grows stronger when their voluntary motivation is stronger of joining a non-profit organization; on the contrary, they tend to leave. For these points, we make some assumptions:

Hypothesis 1: Voluntary motivation is negatively associated with turnover intention. When the members join the organization, the stronger their voluntary motivation is, the lower their turnover intention is, conversely higher.

\subsection{Mediating function of organizational identification}

According to the theory of social identification, people seek for and attach to some group out of potential requirement of self-satisfaction. They have the similar quality and preference with the internal members (Gagné \& Deci, 2005). Once the individual mentally connects its self to one group, the identification to that type is formed. And organizational identification grows on the base of social identification. It's a status in which the individual defines itself in accordance with the membership of one specific group, or a consciousness of belonging to the group. It emphasises that the individual fuses itself into the organization during its process of self-definition. Members like this prefer to be part of the organization, positively keeping their membership, and they have a lower turnover intention. Some past studies have evidenced that organization negatively connects to the members' turnover intention.

In terms of the theory of social identification the members' organizational identification will be affected by individuality, organizational character and environmental character (Chirkoc et al., 2003). In which the individuality contains personal development and the length of service, etc. (Mael \& Ashforth, 1992). People all are looking forward to being a better self. If the institutional arrangement is more consistent with the personal expectation of career development, there is a higher organizational identification (Hall \& Schneider, 1972). And the personal career development is thought as relevant to the personal voluntary motivation of joining one organization. Hence voluntary motivation can be regarded as the antecedent variable of the organization identification. In the youth social organization, most of its participants have a higher voluntary motivation. So we think that with a more intense voluntary motivation, the organizational identification is stronger, while the identification is lower when the motivation is weaker.

Considering these points, we hold a view that voluntary motivation may have a positive influence on the members' organization identification, and what's more it influences their turnover intention. So we can say that organizational identification play a mediating role between voluntary motivation and turnover intention. And we draw some conclusions following:

Hypothesis 2: Organization identification playing part of mediating rule between voluntary and turnover intention. 


\subsection{Regulation of extrinsic motivation}

As the key quality of the modern character, instrumental rationality gradually occupies a place in daily life. In terms of the individuality, the individual in society usually sets the self-development and its motivation as the personal values (Wu Luping, 2007). Now that the non-profit organization is more widely acceptable at home, it's been a stream to join the non-profit organization. The contemporary volunteers have their expectation when they join the voluntary activities (Hustinx, L. 2001). This means that the members of non-profit organization make contribution based on their self-development (Wu Luping, 2007). But we can understand from two contrary sides the influence of extrinsic motivation on the relationship between voluntary motivation and organizational identification: on one side, that extrinsic motivation will enhance the relationship between them; on the other side, it may restrain them. The studies on social psychology release that people's voluntary motivation will be lower when they are under restraint, even lose their realistic initial initiative and positive (Deci et al., 2008). This kind of influence produces a crowding-out effect. And with extrinsic becoming stronger, voluntary motivation's positive effect on organizational identification becomes weaker. As it is, we put forward a pair of competitive assumptions:

Hypothesis 3a: extrinsic motivation is able to negatively moderate the relationship between voluntary motivation and organizational identification. Stronger extrinsic motivation leads to stronger positive influence of voluntary motivation on organization identification, conversely weaker.

Hypothesis3b: extrinsic motivation is able to negatively moderate the relationship between voluntary motivation and organizational identification. Stronger extrinsic motivation leads to weaker positive influence of voluntary motivation on organization identification, conversely stronger.

\section{METHODS}

\subsection{Samples and procedure}

The data comes from the survey files centring on Zhejiang Province. For the exact reliability and efficiency, we've got a general understanding of the turnover condition of the youth social organization members within Zhejiang Province through some talks with the related person in charge, and we've roughly completed the questionnaires through analysis on the files and studies on documents. This essay has chosen 20 youth social organizations to make a pre-survey, so we can make sure the survey's main structure and the words' suitability, and rectify some of the items.

In the way of systematic sampling, the author made a questionnaire survey to 68 youth social organiza- tions within Zhejiang Province in November and December, 2014. There are totally 147 questionnaires given out and 132 received. But for those which are lack of data, we deal with them in the methods following: (1) we talked to people implementing the missing data for the lack of objective information; (2) the questionnaires with 5 or above blank were regarded as unavailable and were excluded after the first step; (3) all of those missing arguments, dependent variables and moderating variables were excluded. Then we finally get 114 available questionnaires with complete data, and the rate of efficiency was $77.5 \%$.

\subsection{Constructional measurement and reliability and validity}

The scaling on variables in the essay all comes from international professional issues, equipped with high reliability and efficiency. And for the semantic consistency of the scaling's measurement, the author invited $2 \mathrm{PhDs}$ major in enterprise management to take a parallel, bidirectional procedure of translation-back translation (Brislin, 1980).

\subsection{Primary variables}

Turnover intention: We use the 4-entry scaling of Chen \& Francesco (2000) to measure, and modify it according to the scene. We estimate with Likert's 5 -poiny scaling where from 1 equals to "agree" to 5 equals to "quite agree". The sampling entry is "I often want to resign from my serving organization" in which reliability (Cronbach's $\alpha$ factor) in the essay is 0.75 .

Voluntary motivation: We use the scaling programmed by Perry. The essay chooses 6 entries with the highest factor loading to measure the motivation of members' self-dedication. We estimate with Likert's 5 -poiny scaling where from 1 equals to "agree" to 5 equals to "quite agree". The sampling entry is "It's more meaningful for me to contribute to the society than to develop myself" in which reliability is 0.834 .

Organizational identification: We use the 6-entry scaling of Mael \& Ashforth (1992), and estimate with Likert's 5-poiny scaling where from 1 equals to "agree" to 5 equals to "quite agree". The sampling entry is "It feels like an insult when somebody criticizes my serving organization" in which reliability is 0.807 .

Instrumental motivation (extrinsic motivation): We choose the 5-entry scaling of Wrzensniewski et al. (2014), and estimate with Likert's 5-poiny scaling where from 1 equals to "agree" to 5 equals to "quite agree". The sampling entry is "I can get a better job when I join my serving organization" in which reliability is 0.776 .

Control variables: In order to control the other influence of explanation mechanism, we take the past studies as reference and limit 5 influential elements of personal layer: age, marriage, educated years, serving 
ICITCE 2015

Table 1.Descriptive statistics and correlations

\begin{tabular}{l|l|l|l|l|l|l|l|l|l|l}
\hline Variables & Mean & SD. & 1 & 2 & 3 & 4 & 5 & 6 & 7 & 8 \\
\hline Age & 30.27 & 8.07 & 1.00 & & & & & & & \\
\hline Marriage & 0.61 & 0.49 & $0.71^{* *}$ & 1.00 & & & & & & \\
\hline Education & 15.96 & 1.96 & $0.36^{* *}$ & $0.39^{* *}$ & 1.00 & & & & & \\
\hline Tenure & 28.17 & 33.07 & $0.60^{* *}$ & $0.38^{* *}$ & -0.30 & 1.00 & & & & \\
\hline Voluntary motivation & 3.80 & 0.73 & $0.25^{* *}$ & -0.16 & -0.13 & $0.21^{* *}$ & 1.00 & & & \\
\hline Organizational identification & 3.83 & 0.72 & $0.31^{* *}$ & $0.27^{* *}$ & $0.09^{*}$ & $0.27^{* *}$ & $0.43^{* *}$ & 1.00 & & \\
\hline Instrumental motivation & 3.86 & 0.66 & 0.00 & -0.09 & 0.04 & -0.04 & $0.25^{* *}$ & $0.45^{* *}$ & 1.00 & \\
\hline Turnover intention & 1.72 & 0.68 & 0.08 & -0.02 & -0.04 & 0.04 & $0.30^{* *}$ & $0.29^{* *}$ & $0.38^{* *}$ & 1.00 \\
\hline
\end{tabular}

$\mathrm{n}=114 ; * * \mathrm{p}<0.05,{ }^{*} \mathrm{p}<0.1$

Table 2. Regression results

\begin{tabular}{|c|c|c|c|c|c|c|c|c|}
\hline & \multicolumn{4}{|c|}{ Organizational identification } & \multicolumn{4}{|c|}{ Turnover intention } \\
\hline & modell & model2 & model3 & model4 & model5 & model6 & model7 & model 8 \\
\hline \multicolumn{9}{|l|}{ Control variables } \\
\hline Age & $\begin{array}{l}0.014 \\
(0.013)\end{array}$ & $\begin{array}{l}0.007 \\
(0.012)\end{array}$ & $\begin{array}{l}0.012 \\
(0.011)\end{array}$ & $\begin{array}{l}0.010 \\
(0.011)\end{array}$ & $\begin{array}{l}0.011 \\
(0.013)\end{array}$ & $\begin{array}{l}0.018 \\
(0.013)\end{array}$ & $\begin{array}{l}0.016 \\
(0.013)\end{array}$ & $\begin{array}{l}0.019 \\
(0.013)\end{array}$ \\
\hline Marriage & \begin{tabular}{|l|}
-0.162 \\
$(0.195)$ \\
\end{tabular} & $\begin{array}{l}-0.202 \\
(0.182) \\
\end{array}$ & $\begin{array}{l}-0.079 \\
(0.168) \\
\end{array}$ & \begin{tabular}{|l|}
-0.122 \\
$(0.168)$ \\
\end{tabular} & $\begin{array}{l}0.094 \\
(0.195) \\
\end{array}$ & \begin{tabular}{|l|}
0.129 \\
$(0.186)$ \\
\end{tabular} & $\begin{array}{l}0.041 \\
(0.186) \\
\end{array}$ & $\begin{array}{l}0.081 \\
(0.183) \\
\end{array}$ \\
\hline Education & \begin{tabular}{|l|}
0.019 \\
$(0.037)$ \\
\end{tabular} & $\begin{array}{l}0.026 \\
(0.034) \\
\end{array}$ & $\begin{array}{l}0.015 \\
(0.031) \\
\end{array}$ & $\begin{array}{l}0.011 \\
(0.031) \\
\end{array}$ & $\begin{array}{l}-0.009 \\
(0.037) \\
\end{array}$ & \begin{tabular}{|l|}
-0.015 \\
$(0.035)$ \\
\end{tabular} & $\begin{array}{l}-0.003 \\
(0.035) \\
\end{array}$ & $\begin{array}{l}-0.008 \\
(0.034) \\
\end{array}$ \\
\hline Tenure & $\begin{array}{l}0.003 \\
(0.002)\end{array}$ & $\begin{array}{l}0.002 \\
(0.002)\end{array}$ & $\begin{array}{l}0.003 \\
(0.002)\end{array}$ & $\begin{array}{l}0.003 \\
(0.002)\end{array}$ & $\begin{array}{l}-0.001 \\
(0.003)\end{array}$ & \begin{tabular}{|l|}
0.000 \\
$(0.002)$
\end{tabular} & $\begin{array}{l}0.001 \\
(0.002)\end{array}$ & $\begin{array}{l}0.001 \\
(0.002)\end{array}$ \\
\hline \multicolumn{9}{|l|}{ Dependent variable } \\
\hline Voluntary motivation & & $\begin{array}{l}0.368 * * * \\
(0.088) \\
\end{array}$ & $\begin{array}{l}0.253 \\
(0.084) \\
\end{array}$ & \begin{tabular}{|l|}
$0.244 * * *$ \\
$(0.083)$ \\
\end{tabular} & & \begin{tabular}{|l|}
$-0.317 * * *$ \\
$(0.090)$ \\
\end{tabular} & & $\begin{array}{l}-0.229 * * \\
(0.095)\end{array}$ \\
\hline \multicolumn{9}{|l|}{ Mediate variable } \\
\hline Organizational identification & & & & & & & $\begin{array}{l}-0.326^{* * *} \\
(0.092) \\
\end{array}$ & $\begin{array}{l}-0.238 * * \\
(0.097) \\
\end{array}$ \\
\hline \multicolumn{9}{|l|}{ Independent variable } \\
\hline Instrumental motivation & & & $\begin{array}{l}0.418^{* * *} \\
(0.089)\end{array}$ & $\begin{array}{l}0.404 * * * \\
(0.088)\end{array}$ & & & & \\
\hline \multicolumn{9}{|l|}{ Interaction } \\
\hline $\begin{array}{l}\text { Instrumental motivation* Voluntary } \\
\text { motivation }\end{array}$ & & & & \begin{tabular}{|l|}
$-0.156^{*}$ \\
$(0.090)$ \\
\end{tabular} & & & & \\
\hline $\mathrm{R}^{2}$ & 0.113 & 0.238 & 0.370 & 0.387 & 0.009 & 0.112 & 0.114 & 0.160 \\
\hline$\Delta \mathrm{R}^{2}$ & & 0.125 & 0.132 & 0.017 & & 0.103 & 0.105 & 0.046 \\
\hline F value & $3.438 * * *$ & $6.674 * * *$ & $10.367 * * *$ & $9.48 * * *$ & 0.246 & $2.700 * *$ & $2.750 * *$ & $3.369 * * *$ \\
\hline$\Delta \mathrm{F}$ & & $17.717 * * *$ & $22.419 * * *$ & $2.940 * * *$ & & $12.527 * *$ & $12.799 * *$ & $5.860 * * *$ \\
\hline
\end{tabular}

time (months).

\section{ANALYSIS OF DATA AND ITS RESULTS}

\subsection{Descriptive statistical analysis on variables}

The Table 1 summaries the average value, variance and related factors of variables.

\subsection{Hypothesis tests}

The essay mainly takes SPSS18.0 to process hierarchical regression for the associated hypothesis tests. The result is listed in the Table 2.

Main effect: the assumption 1 poses the obvious negative influence of voluntary motivation on turnover intention. To verify these two assumptions, we first set turnover intention as the dependent variable, and then we add the control variables (age, marriage, educated years and serving time), at last we put the argument (voluntary motivation) into the regression equation. Its result is listed in the Table 2 from which we can see voluntary motivation has an obvious positive influence on turnover intention $\left(\mathrm{M}_{6}, \beta=-0.317, p\right.$ $<0.01)$. Therefore, the assumption 1 is supported by data.

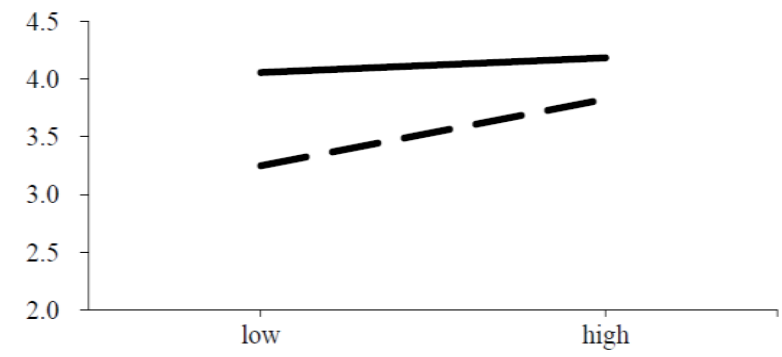

Figure 1. The moderation of instrumental motivation

Mediating effect: We can tell from the Table 2, 
voluntary motivation has an obvious negative influence on turnover intention $\left(\mathrm{M}_{6}, \beta=-0.317, p<0.01\right)$. Meanwhile, organizational identification has an obvious negative influence on turnover intention $\left(\mathrm{M}_{7}, \beta=\right.$ $0.326, \mathrm{p}<0.05$ ). After adding the mediating variable of organizational identification, voluntary motivation still has an obvious influence on turnover intention $\left(\mathrm{M}_{8}, \beta=-0.229, \mathrm{p}<0.05\right)$, and organizational identification still has an obvious negative influence on turnover intention $\left(\mathrm{M}_{8}, \beta=-0.238, \mathrm{p}<0.05\right)$. So we can draw a conclusion that organizational identification of the youth social organization members plays its partially mediating role between voluntary motivation and turnover intention, which supports the assumption 2. And the essay uses Sobel's approach to verify the significance of the mediating effect (Sobel, 1982). Its result shows that organizational identification plays its mediating role between voluntary motivation and turnover intention $(Z=-2.703, p<0.01)$.

Moderating effect: the assumption 3 poses that the extrinsic motivation (instrumental motivation) will moderate the positive relationship between voluntary motivation and organizational identification. To verify it, we set organizational identification as dependent variable first, and then successively add the control variables, argument (voluntary motivation) and moderating variable (extrinsic motivation), finally come the product terms of argument and moderating variable. In order to eliminate the collinearity, during the process we construct the product terms of argument and moderating variable, we standardize the argument and moderating variable. We can see the model 4 in the Table 2 , the interaction item of voluntary motivation and extrinsic motivation have an obvious negative influence on organizational identification $\left(\mathrm{M}_{4}, \beta=\right.$ $-0.156, p<0.1)$ which indicates that the higher the extrinsic motivation of the youth volunteers is, the weaker positive relationship is between voluntary motivation and organizational identification. Thus the assumption 3 is verified. The Figure 1 shows the influential mode of this interaction. We describe respectively the difference of voluntary motivation's influence on organizational identification with a standard deviation above the average and one below the average, when the members' extrinsic motivation is different from each other's.

\subsection{Analysis on homologous variance}

Because the questionnaires of this study were made by the self-estimation of social organization management, the homologous variance should be taken in consideration. To avoid it, we control and test from the following two aspects: (1) we try to separate the questions of argument and dependent variable in terms of the questionnaires' structure and recall to let the participants consider less about its aim. (2) we take Harman single -factor test. We put 4 constructional entries together to have an exploratory factor analysis.
The first irrotational factor explains $30.964 \%$ of the variance, and the 4 factors totally explain $64.693 \%$. Though the first irrotational factor explains the biggest variance, but that isn't more than a half the explained variance. Additionally, some scholars point out that if the interaction effect is significant during the process of analysing data, the problem of homologous deviation does not exist. In the study, extrinsic motivation plays its moderating role to the relationship between voluntary motivation and organizational identification, that's why our homologous deviation is acceptable.

\section{CONCLUSION AND REVELATION}

\subsection{Conclusion}

The essay sets 114 youth social organization as surveying objects, and empirically testifies the function mechanism on turnover intention of voluntary motivation of the members joining youth voluntary non-profit organization. The result shows: (1) voluntary motivation is an important source of organizational identification for non-profit organization and it tells that most of the young people joining social organization have a public spirit and an ambition of caring about the social vulnerable group; (2) organizational identification has an obvious negative influence on turnover intention, which reveals that it's an important part to strengthen organizational identification for less brain drain; (3) extrinsic motivation moderates the relationship between voluntary motivation and organizational identification. That's to say, when the members have a higher level of extrinsic motivation, the influence of extrinsic motivation on organizational identification will shrinks; when they have a lower level of extrinsic motivation, strengthening the relationship between voluntary motivation and organizational identification, and it restrains their turnover intention further.

\subsection{Contributions}

From the perspectives of voluntary motivation for individual to join a voluntary organization, the essay wholly considers the crowding-out effect of extrinsic motivation of the individual joining non-profit organization, deeply analysing voluntary motivation's function mechanism to individual turnover intention. And we understand that the explanation of individual behaviour should be on the base of multiple values but not favour one more than another. Individual behavioural motivation is complex and multiple. Any analysis that separates voluntary motivation and extrinsic motivation of individual behaviour gets nothing but a one-sided result;

It opens the black box between individual's motivations of joining voluntary non-profit organization. In the past, the studies only analysed the influence on 
individual turnover intention from a perspective of voluntary motivation, but ignored the moderating role of individual extrinsic motivation to the relationship between voluntary motivation and organizational identification. As it sets extrinsic motivation of individual who joins non-profit organization as the moderating variable, the essay wholly analyses the turnover intention's function mechanism of individual motivation. It has certain theoretical meaning.

\subsection{Revelation of management}

Because of its specific organizational quality, non-profit organization is an organization in a large extent combined by the members who have the same values and a strong organizational identification, which features of emotion (Zhang Ran \& Funridis Neumann, 2012). So the staff-oriented emotional management helps more in strengthening organization's emotion, lowering their turnover intention. Practically, the organization can make its voluntary service spirit deeper in mind as well as encourages the members to internalise the voluntary spirit into a public resonation through propagating voluntary spirit and developing an internal voluntary culture.

As the acceptance of non-profit organization goes higher and higher at home, it will get a high social acknowledge by joining this kind of organization. But according to our study, voluntary motivation's positive function to organizational identification can be negatively moderated by extrinsic motivation. So while recruiting the participants, we should focus on those who have a higher level of voluntary motivation, and estimate it for choosing the members fitting the organization's values well helping it develop better.

A good practice of human resource can efficiently raise organizational identification. By now, the management of human resource in the youth social organization is a bit weak yet. It even does not exist in many youth social organizations, which immensely affects the members' organizational identification. The management should make full use of the implicit intensive (trust intensive, work intensive, honour intensive) to rise up the members' sense of honour, identification and their satisfaction. To unite the staff closely through an organizational structure improved so as to ensure that the voluntary service can be sustainably undergone in the long term.

\subsection{Deficiency and forecast}

Based on the sample of Zhejiang Province, the essay undertakes a study to voluntary motivation and turnover intention of the members of youth social organization. Of course, there is some deficiency inevitably. First, the quantity of our samples is a little small, which limits the spreading of the conclusion. Moreover, the data mostly comes from Zhejiang Province; the extrinsic efficiency may be influenced.
The future study can be improved in three aspects: on data collection, we can enlarge the collected area, and we can collect in different periods to avoid the homologous deviation; on comment studied, we can focus further on and testify the moderating role of individual's turnover intention to the cultural factors (collectivism, individual tradition); on the study methods, though the study excludes all possibilities that the results will be influenced by homologous deviation through a series of tests. But out of the academic rigour, data collection multi-sources and different periods should be considered in the future studies, so that to avoid the homologous deviation fundamentally (Li Yanping \& Tu yidong, 2012). In addition, the methods of longitudinal and cross-level research can be further applied to make the outcome more perfect and enhance the quality.

\section{REFERENCES}

[1] Brislin, R. W. 1980. Translation and content analysis of oral and written material. Handbook of cross-cultural psychology, 2(2):349-444.

[2] Chen, Z. X. \& Francesco, A. M. 2000. Employee demography, organizational commitment, and turnover intentions in China: do cultural differences matter? Human relations, 53(6): 869-887.

[3] Chirkov, V., Ryan, R. M., Kim, Y. \& Kaplan, U. 2003. Differentiating autonomy from individualism and independence: a self-determination theory perspective on internalization of cultural orientations and well-being. Journal of personality and social psychology, 84(1):97.

[4] Clary, E. G. \& Snyder, M. 1999. The motivations to volunteer theoretical and practical considerations. Current directions in psychological science, 8(5):156-159.

[5] Deci, E. L., Koestner, R. \& Ryan, R. M. 1999. A meta-analytic review of experiments examining the effects of extrinsic rewards on intrinsic motivation. Psychological bulletin, 125(6): 627.

[6] De Vita, C. J., Twombly, E. C. \& Montilla, M. D. 2002. Toward Better Child Care Worker Compensation: Advocacy in Three States.

[7] Gagné, M. \& Deci, E. L. 2005. Self-determination theory and work motivation. Journal of Organizational behavior, 26(4): 331-362.

[8] Hall, D. T. \& Schneider, B. 1972. Correlates of organizational identification as a function of career pattern and organizational type. In Academy of Management Proceedings, (1): 159-161.

[9] Hom, P. W. \& Griffeth, R. W. 1995. Employee turnover. South-Western Pub.

[10] Hustinx, L. 2001. Individualisation and new styles of youth volunteering: An empirical exploration. Voluntary Action, 3(2): 57-76.

[11] Lester, S. W., Meglino, B. M. \& Korsgaard, M. A. 2008. The role of other orientation in organizational citizenship behavior. Journal of Organizational Behavior, 29(6): 829.

[12] Mael, F. \& Ashforth, B. E. 1992. Alumni and their alma mater: A partial test of the reformulated model of organizational identification. Journal of organizational Behavior, 13(2): 103-123. 
[13] Maertz, C. P. \& Boyar, S. L. 2012. Theory-driven development of a comprehensive turnover-attachment motive survey. Human Resource Management, 51(1):71-98.

[14] Perry, J. L. 1996. Measuring public service motivation: An assessment of construct reliability and validity. Journal of Public Administration Research and Theory, 6(1): 5-22.

[15] Price, J. L. 2001. Reflections on the determinants of voluntary turnover. International Journal of Manpower, 22(7): 600-624.

[16] Porter, L. W. \& Lawler, E. E. 1968. Managerial Attitudes and Performance.

[17] Salamon, L. M. \& Geller, S. L. 2007. The nonprofit workforce crisis: Real or imagined. Listening Post Project.

[18] Sobel, M. E. 1982. Asymptotic confidence intervals for indirect effects in structural equation models. Sociological methodology, 13: 290-312.

[19] Wrzesniewski, A., Schwartz, B., Cong, X., Kane, M., Omar, A. \& Kolditz, T. 2014. Multiple types of motives don't multiply the motivation of West Point cadets. Proceedings of the National Academy of Sciences, 111(30): 10990-10995.

[20] Yousaf, A., Yang, H. \& Sanders, K. 2015. Effects of intrinsic and extrinsic motivation on task and contextual performance of Pakistani professionals: the mediating role of commitment foci. Journal of Managerial Psychology, 30(2): 133-150.

[21] Li Yanping \& Tu Yidong. 2012. Study on value orientation of organizational citizenship behavior. Management World, (5): 1-7.

[22] Wu Luping. 2007. Types and structures of volunteers' motivation--Interviews analysis towards 24 young volunteers. Research of Youth, (5): 31-40.

[23] Zhang Ran \& Meredith A. Newman. 2012. Emotional labour and its management: A new perspective of human resource management (HRM) for not-for-profit (NFP) organizations. Journal of Zhejiang University (Humanities and Social Sciences), 42(2): 5-21 